\title{
Structural and phase evolution in mechanically alloyed calcium copper titanate dielectrics
}

\author{
Morteza Alizadeh $^{\mathrm{a}, *}$, Hamed Ahmadi Ardakani ${ }^{\mathrm{a}}$, Rasool Amini ${ }^{\mathrm{a}}$, \\ Mohammad Reza Ghazanfari ${ }^{\mathrm{a}}$, Mohammad Ghaffari ${ }^{\mathrm{b}}$ \\ ${ }^{a}$ Department of Materials Science and Engineering, Shiraz University of Technology, 3619995161 Shiraz, Iran \\ ${ }^{\mathrm{b}}$ Department of Electrical and Electronics Engineering, UNAM-National Institute of Materials Science and Nanotechnology, Bilkent University, Ankara \\ 06800, Turkey
}

Received 29 April 2012; received in revised form 4 October 2012; accepted 5 October 2012

Available online 29 October 2012

\begin{abstract}
Nanocrystalline calcium-copper-titanate (CCTO) dielectric powders were prepared by mechanical alloying. Phase transformations and structural evolution of the mechanically activated powders were investigated through the Rietveld refinement of the X-ray diffraction results. The crystallite size, lattice strain, and weight fraction of individual phases were estimated based on crystal structure refinement. Furthermore, the microstructural properties and thermal behavior of the milled powders were investigated by Transmission Electron Microscopy (TEM) and Differential Thermal Analysis (DTA), respectively. It was found that CCTO nanocrystals can be successfully synthesized after the amorphization of the initial crystalline materials. Semi-spherical nano-size particles were developed after sufficient milling time. Formation of an amorphous phase during the milling cycle was confirmed by the presence of the glass transition and crystallization peaks in the thermal analysis profiles.
\end{abstract}

(c) 2012 Elsevier Ltd and Techna Group S.r.l. All rights reserved.

Keywords: C. Thermal properties; Mechanical alloying; Dielectrics; Amorphous phase

\section{Introduction}

The extraordinary high dielectric constant of calcium copper titanate (CCTO) was discovered for the first time by Subramanian et al. in 2000 [1]. The dielectric constant of CCTO is almost temperature independent, with a temperature range between $100 \mathrm{~K}$ and $600 \mathrm{~K}$ [2-4]. It also has a very small frequency dependence of up to $10^{5} \mathrm{~Hz}$ $[5,6]$. Such weak temperature and frequency dependencies for CCTO's dielectric constant have attracted much researcher interest because it is an ideal material in a wide range of applications, especially in microelectronics [2-8].

To date, synthesis of CCTO has been performed by either mixed oxides [1-3,7], chemical [4,9-11], or mechanical routes [12]. CCTO ceramics are most often produced through conventional mixed oxide methods. However, this process has a tendency to produce coarse particles with

\footnotetext{
*Corresponding author. Tel.: +98 711 7354500; fax: +98 7117354520 .

E-mail address: Alizadeh@sutech.ac.ir (M. Alizadeh).
}

compositional inhomogeneity in addition to the formation of particle agglomerates/aggregates in the resulting powder. Consequently, the sinterability of the powders is considerably reduced $[9-11,13,14]$. Furthermore, it should be noted that in order to achieve the desired CCTO phase, calcination at elevated temperatures is crucial $[4,9]$. In spite of the suitable properties achieved through this method [4], broader application of chemical synthesis is also limited due to high precursor costs. Mechanical alloying (MA) is a solid state technique which is widely used to synthesize advanced materials such as intermetallic compounds and alloys [15], nanostructured materials, and supersaturated solid solutions [16-18]. The main advantage of the method is that solid-state reactions are activated via the introduction of mechanical energy instead of temperature. Consequently, the chemical reactivity of starting materials is improved significantly after an appropriate mechanical alloying treatment. Moreover, the calcination temperature for the formation of desirable phases can be reduced considerably and in some cases the desired structures 
may be formed directly via MA without any subsequent heat treatment [19]. However, contamination issues found in the MA process have been known to compromise the final property of the material, preventing this method from being widely utilized. As a consequence, care should be taken whenever the method is used in materials processing. Recently, MA has been applied in the processing of ceramic materials such as lead zirconate titanate [13], lead zinc niobate [15], lead magnesium niobate [20,21], lead magnesium niobate-lead titanate [22,23], and barium titanate [14,20,24].

Almeida et al. were the first to study the synthesis of CCTO through MA of pure $\mathrm{CaCO}_{3} / \mathrm{Ca}(\mathrm{OH})_{2}, \mathrm{CuO}$, and $\mathrm{TiO}_{2}$ precursors [12]. Later, Manik and Pradhan [25] investigated the structural properties of CCTO electroceramics produced via high energy milling. In the present work, the microstructure and thermal properties of CCTO electroceramics synthesized by mechanical alloying (MA) are studied. The novelty of this paper is the utilization of Rietveld method of quantifying the structural properties of both amorphous and crystalline phases, as well as the detection of glass transition behavior prior to amorphous phase crystallization during the heating cycle.

\section{Experimental procedure}

To synthesize the CCTO compound, high purity initial materials consisting of $\mathrm{TiO}_{2}$ (Merck, $>99.9 \%, D_{\text {ave }}=250$ nm), $\mathrm{CaO}$ (Merck, >99.9\%, $D_{\text {ave }}=310 \mathrm{~nm}$ ), and $\mathrm{CuO}$ (Merck, $>99.5 \%, D_{\text {ave }}=680 \mathrm{~nm}$ ) were mixed according to the stoichiometric ratio of CCTO. Powders were sufficiently mixed and then milled by a laboratory planetary ball mill (Sepahan $84 \mathrm{D}$ ) in a tempered steel vial with steel balls $(4 \times 20 \mathrm{~mm}$ and $8 \times 10 \mathrm{~mm})$. The milling process was accomplished under dry conditions with a rotational speed of $250 \mathrm{rpm}$ and the ball-to-powder weight ratio of 20:1. Powders were milled for up to $300 \mathrm{~h}$.

Phase development during the milling cycle was analyzed by an X-ray diffractometer (XRD, Bruker Advance 2 ) using $\mathrm{CuK} \alpha_{1,2}$ radiation. The data was collected at room temperature with a $2 \theta$ range between $20^{\circ}$ and $60^{\circ}$ with the step size and scan rate of $0.03^{\circ}$ and $6 \mathrm{~s}$, respectively. The $\mathrm{X}$-ray tube was operated at $40 \mathrm{kV}$ and $40 \mathrm{~mA}$. In the present study, Rietveld refinement of XRD patterns were done using MAUD software (by Luca Lutterotti, 19972011, University of Trento-Italy) and the required structural and microstructural information of the individual phases were then extracted. In addition, differential thermal analysis (DTA, Shimadzu, Japan) was performed on the as-milled powders at the temperature range of 100 $1000{ }^{\circ} \mathrm{C}$ and heating rate of $20-30{ }^{\circ} \mathrm{C} / \mathrm{min}$. In order to evaluate the powders microstructure as well as their size distribution, transmission electron microscopy (TEM, JEOL-JEM 2010) was also performed on the selected powders. Finally, in order to determine the variation of particle size distribution during the milling cycle, the nanoparticle size analyzer (Vasco DLS Particle Size Analyzer, Kunash Instruments) was utilized.

\section{Method of structural analysis}

Phase quantification was carried out in two steps. In the first step, the amount of the crystalline phase was determined through the Rietveld refinement of XRD patterns followed by the quantification of the amorphous phase through a method proposed by Winburn et al. [26] based on Rietveld quantitative analysis [27-30]. In the latter step, an internal standard composed of a fully crystalline powder with an X-ray absorption edge similar to CCTO was mixed with a predetermined amount of our alloyed powder, after which XRD analysis was conducted on the resulting powder mixtures. The amorphous phase fraction was estimated by the difference between the measured and expected values of the standard powder. In the present study, a fully crystalline vanadium oxide $\left(\mathrm{V}_{2} \mathrm{O}_{5}\right)$ powder with a median crystallite size of $45 \mathrm{~nm}$ was used as the standard.

A Rietveld profile fitting method was established to characterize the structure of mechanically activated powders synthesized under different milling durations using Rietveld analysis software. Experimental profiles were fitted with the most desirable pseudo-Voigt analytical function taking into consideration both crystallite size and strain broadening [31]. It should be noted that structural and microstructural refining can be simultaneously carried out by this software. Using this method, parameters such as lattice constant $(a)$, phase percentages, crystallite sizes $(D)$, lattice microstrain (r.m.s. strain) can be estimated quite accurately [32,33].

During refinement, peak positions were initially modified by correcting zero point and sample displacement errors. Refinement of fundamental parameters such as unit cell dimensions, scale factor, crystallite size, and lattice strain was performed for each phase. Marquardt leastsquares procedure was utilized to minimize the difference between the observed and calculated patterns. In addition, the refining process was carried out through the use of the reliability index parameter $\left(R_{\mathrm{wp}}\right)$ and Bragg factor $\left(R_{B}\right)$ defined as:

$$
\begin{aligned}
& R_{\mathrm{wp}}=\left[\frac{\sum_{i} w_{\alpha}\left(I_{o}-I_{c}\right)^{2}}{\sum_{\alpha} w_{\alpha} I_{o}^{2}}\right]^{1 / 2} \\
& R_{B}=100\left(\frac{\sum\left|I_{o}-I_{c}\right|}{\sum I_{o}}\right)
\end{aligned}
$$

where $I_{o}$ and $I_{c}$ are the observed and calculated intensity and $w_{\alpha}=1 / I_{o}$ is the weight of the experimental observations. The quality of the fitting was also evaluated by using a goodness of fit factor $(S)$ which is estimated by the $R_{\mathrm{wp}}$-to- $R_{\mathrm{ex}}$ fraction, in which $R_{\mathrm{ex}}$ is the expected error calculated as follows:

$R_{\exp }=\left[\frac{N-P}{\sum_{\alpha} w_{\alpha} I_{o}^{2}}\right]^{1 / 2}$

where $N$ and $P$ are the number of experimental observations and fitting parameters, respectively. The refining is 
performed consecutively, provided that $R_{\mathrm{wp}}$ reaches quantities less than $10 \%$ and $S$ approaches 1 .

Quantitative values for phases found in our multicomponent powders were estimated through the use of scale factors. The weight fraction of constituent phases was calculated using the following formula:

$x_{i}=S_{\alpha} Z_{\alpha} M_{\alpha} V_{\alpha} / \sum_{\beta} S_{\beta} Z_{\beta} M_{\beta} V_{\beta}$

where $S_{\alpha}, Z_{\alpha}, M_{\alpha}$, and $V_{\alpha}$ are the Rietveld scale factor, the number of formula units per unit cell, the molecular weight and the unit-cell volume of a given phase, respectively.

Finally, crystallite size and lattice analyses were analyzed through the pseudo-Voigt function which simultaneously considers the contribution of crystallite size and lattice microstrain on the line broadening of XRD peaks [32-34].

\section{Results and discussion}

The XRD spectra of powders milled under different durations are presented in Fig. 1. As observed, the sharpness of the diffraction peaks found in the initial powder mixture gradually becomes reduced during the milling process. This can be attributed to a decrease in crystallite sizes as well as an increase in lattice strain.

The rate of peak broadening is not the same for all phases, and it is quite severe for $\mathrm{CuO}$ and $\mathrm{CaO}$. The peaks associated with these initial phases vanish at a different rate as well. For instance, $\mathrm{Ca}(\mathrm{OH})_{2}$ peaks, presented in the initial powder mixture due to $\mathrm{CaO}$ moisture absorption, vanish after $16 \mathrm{~h}$ of milling and, followed by $\mathrm{CuO}, \mathrm{CaO}, \mathrm{a}^{-\mathrm{TiO}_{2}}$, and $\mathrm{r}-\mathrm{TiO}_{2}$. All precursor compounds totally dissolve into the final structure by the end of the milling cycle. As milling progresses, crystal strain increases atomic plane spacing, resulting in XRD peak shifts to lower angles. Also, highangle peaks disappear due to the presence of large amounts of amorphous phase in the structure [35]. Peak broadening as well as overlapping, due to the presence of nano-sized structures, lattice strain, and amorphous phases, hinder the proper identification of the features seen through XRD.

After milling for $128 \mathrm{~h}$, CCTO's structure becomes predominantly amorphous. This is confirmed through the featureless appearance of the high resolution TEM micrograph of the CCTO nanoparticles, as well as the diffuse halo pattern of the corresponding selected area diffraction (SAD) pattern presented in Fig. 2. However, after $192 \mathrm{~h}$ of milling, a perovskite phase of CCTO begins to nucleate from the amorphous phase. This can be seen by the appearance of the (220) peak at $2 \theta=34^{\circ}$ on the XRD spectra. As a result of further mechanical activation, additional crystalline diffractions peaks appear, with intensities proportional to milling duration. After $32 \mathrm{~h}$ of milling, the material displays a very broad peak around $2 \theta=32^{\circ}$. This is related to the metastable srilankite $\left(\mathrm{s}-\mathrm{TiO}_{2}\right)$ produced from the polymorphic transformation of a- $\mathrm{TiO}_{2}$ during MA. It has been previously observed that the diffraction peaks of srilankite are usually broadened

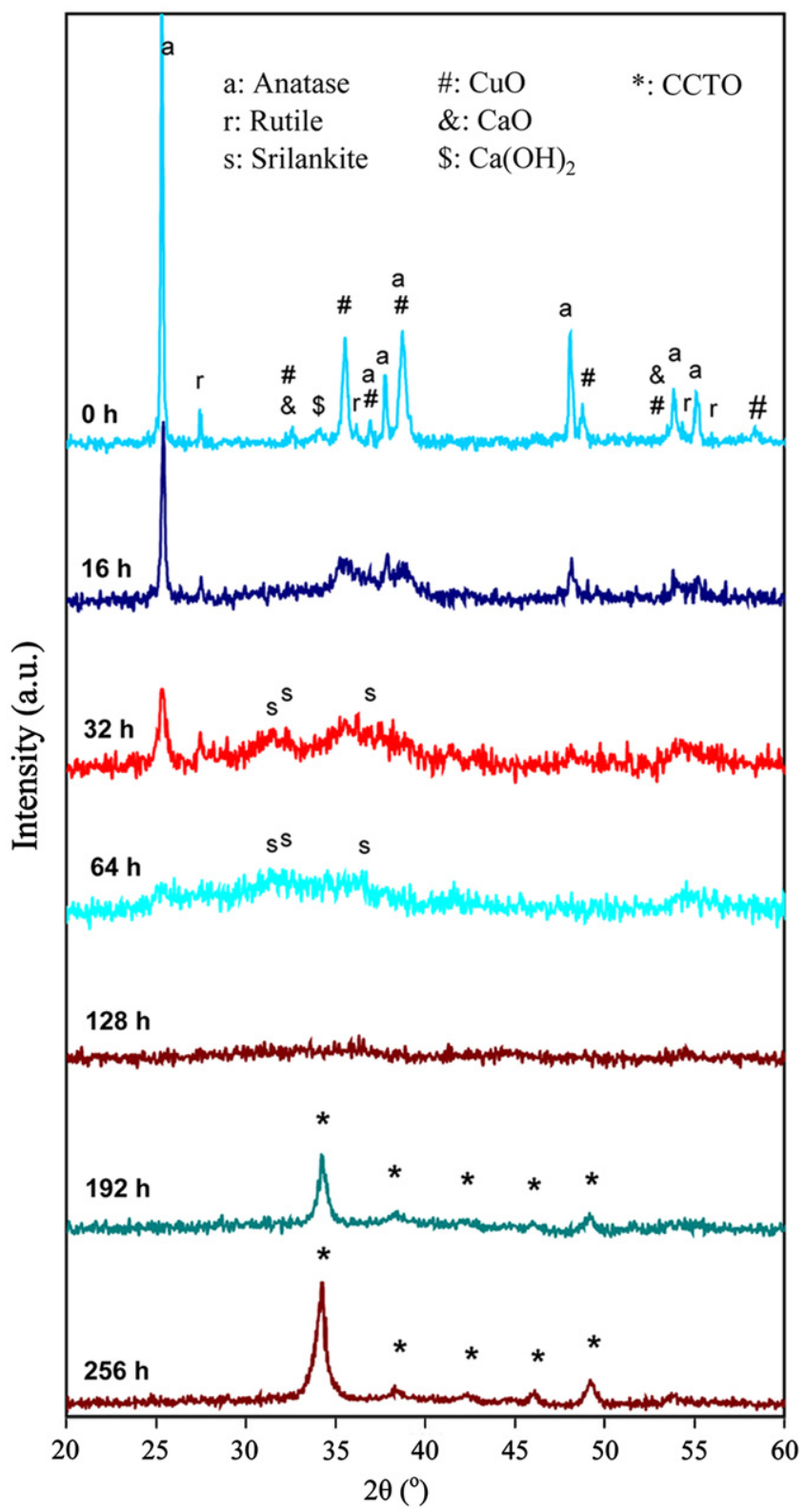

Fig. 1. X-ray diffraction patterns of the initial and as-milled powder mixtures.

due to nanometric crystallites containing a large amount of lattice strain [36-38].

The weight percent, crystallite size, and lattice strain of the phases present under different milling durations, extracted from Rietveld refinement analysis are presented in Table 1, Figs. 3 and 4, respectively.

Initially crystallite sizes of the precursor materials are reduced rapidly then decreased more gradually until complete amorphization at $128 \mathrm{~h}$, see Fig. 3. The grain refinement rate of precursor materials is significantly different, possibly due to the difference in the crystalline lattice energy and melting point $[21,39,40]$. As a result of further milling, CCTO with an average crystallite size of $13 \mathrm{~nm}$ is formed and its crystallite size approaches $24 \mathrm{~nm}$ after $256 \mathrm{~h}$ of milling. 


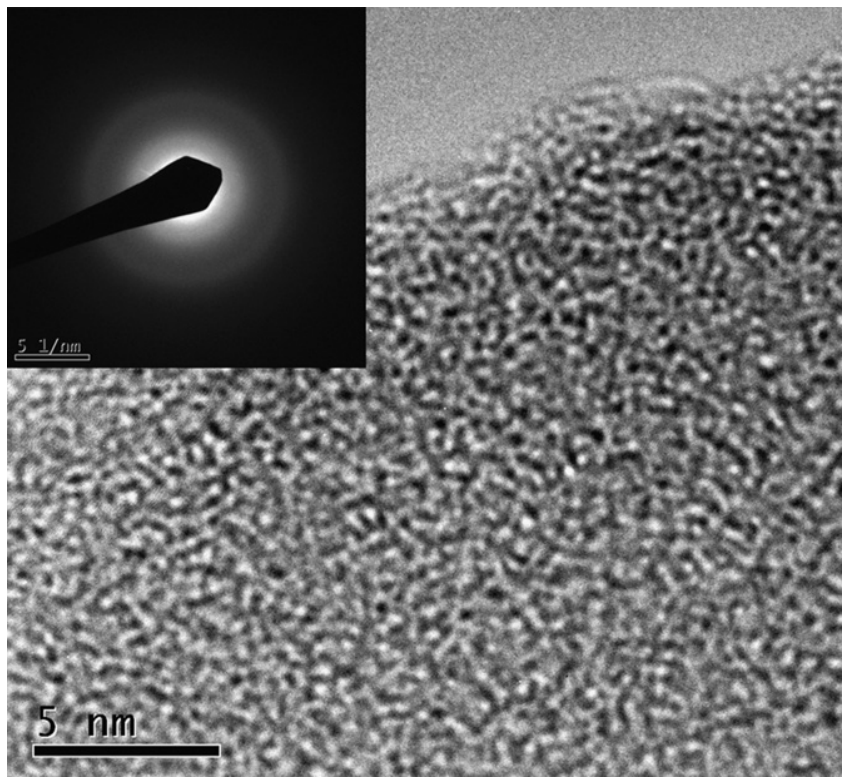

Fig. 2. The high resolution TEM image and the corresponding selected area diffraction (SAD) pattern of $128 \mathrm{~h}$ milled powders.

Table 1

The weight percent of the detected phases at the different milling times.

\begin{tabular}{|c|c|c|}
\hline Milling time & Detected phases & Weight percent $(\%)$ \\
\hline \multirow[t]{6}{*}{0} & Anatase & 16.16 \\
\hline & Rutile & 6.61 \\
\hline & $\mathrm{CuO}$ & 38.2 \\
\hline & $\mathrm{CaO}$ & 6.61 \\
\hline & $\mathrm{Ca}(\mathrm{OH})_{2}$ & 1.89 \\
\hline & Amorphous content & 30.53 \\
\hline \multirow[t]{6}{*}{16} & Anatase & 32.8 \\
\hline & Rutile & 3.12 \\
\hline & Srilankite & - \\
\hline & $\mathrm{CuO}$ & 15.25 \\
\hline & $\mathrm{CaO}$ & 2.55 \\
\hline & Amorphous content & 45.73 \\
\hline \multirow[t]{6}{*}{32} & Anatase & 10.15 \\
\hline & Rutile & 1.54 \\
\hline & Srilankite & 8 \\
\hline & $\mathrm{CuO}$ & 8.22 \\
\hline & $\mathrm{CaO}$ & 1.58 \\
\hline & Amorphous content & 71.22 \\
\hline \multirow[t]{5}{*}{64} & Anatase & 3.29 \\
\hline & Rutile & 2.58 \\
\hline & Srilankite & 1.25 \\
\hline & $\mathrm{CaO}$ & 1.42 \\
\hline & Amorphous content & 91.46 \\
\hline \multirow[t]{2}{*}{128} & Rutile & 1.71 \\
\hline & Amorphous content & 98.29 \\
\hline \multirow[t]{2}{*}{192} & ССТО & 61.65 \\
\hline & Amorphous content & 38.35 \\
\hline \multirow[t]{2}{*}{256} & ССТO & 88.57 \\
\hline & Amorphous content & 11.43 \\
\hline
\end{tabular}

Fig. 4 indicates the lattice strain of the phases at different milling durations. As can be seen, by starting the milling process, due to the impact force of the grinding media, strain is introduced into the crystals lattice and consequently the micro-strain of the primary materials is

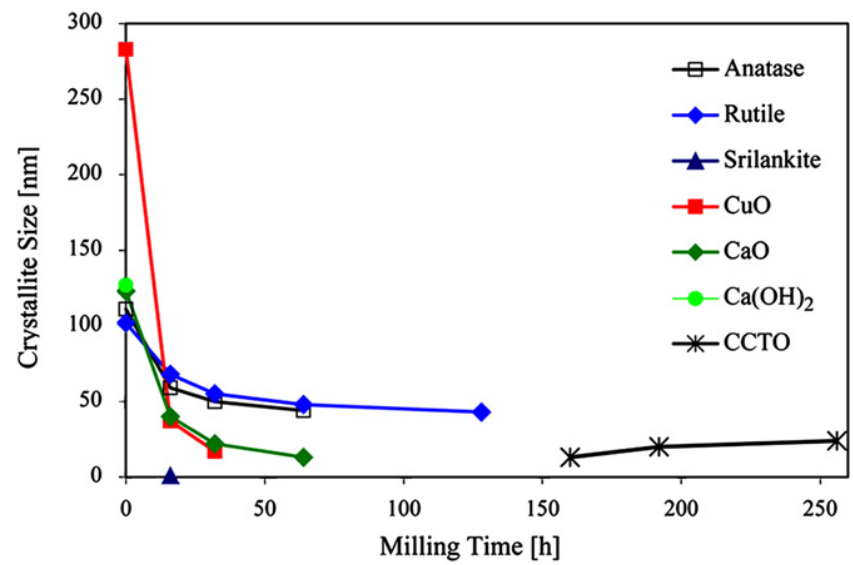

Fig. 3. Crystallite size variation of the primary materials and CCTO phase during milling.

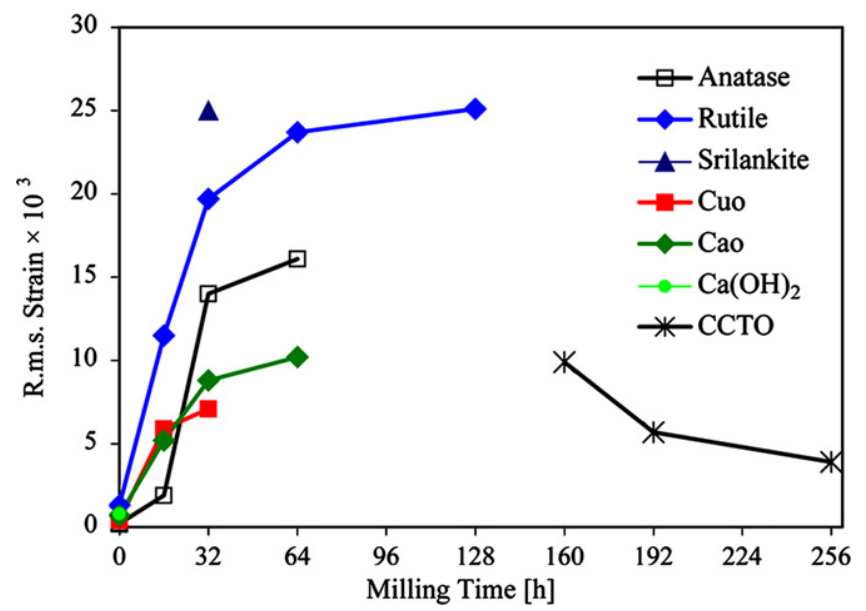

Fig. 4. Lattice strain of the primary materials and CCTO phase as a function of milling time.

increased significantly. The lattice strain increase continues with milling progression, albeit with an inferior rate, until complete amorphization. Subsequently, by milling from $160 \mathrm{~h}$ to $256 \mathrm{~h}$, the chemical composition of nanocrystals nucleated from the amorphous phase approaches the CCTO stoichiometry and consequently the lattice strain of crystalline CCTO is reduced from $9.9 \times 10^{-3}$ to $3.9 \times 10^{-3}$

DTA results of the powders mechanically activated for $32 \mathrm{~h}, 128 \mathrm{~h}$, and $256 \mathrm{~h}$ are shown in Fig. 5. Two exothermic peaks are observed in the DTA trace for the powders which were milled for $32 \mathrm{~h}$ : (1) a sufficiently broad peak centered at $200{ }^{\circ} \mathrm{C}$ is related to stress relaxation, which retards the strain energy of the system [4]; (2) a peak centered at $700{ }^{\circ} \mathrm{C}$ is correlated to the transition of the amorphous phase to the more stable crystalline CCTO compound. As can be seen, the broadening and intensity of the peak ascribed to stress relaxation is considerably increased when the material is milled for $128 \mathrm{~h}$ and is significantly reduced by the end of the milling cycle ( $256 \mathrm{~h}$ ). This confirms the micro-strain results previously reported 


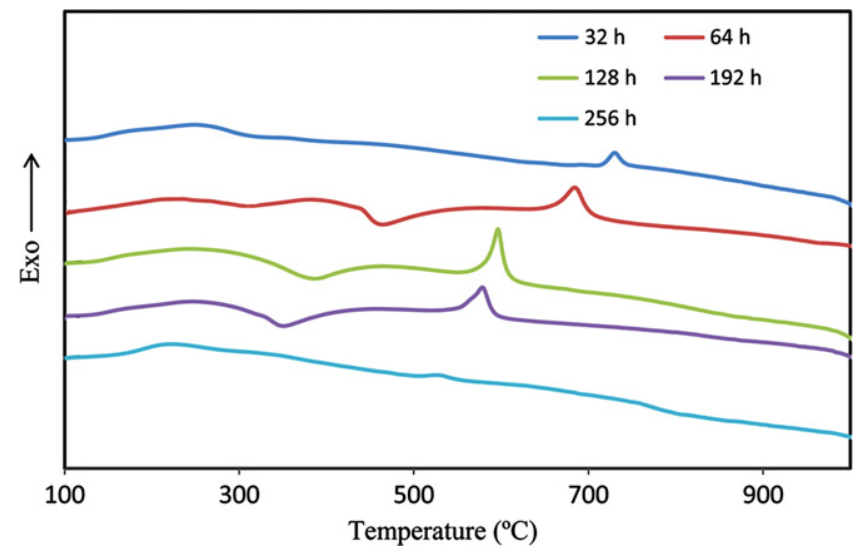

Fig. 5. The DTA results of mechanically activated powders for different times of milling.

Table 2

The variations of the powder particle size at the different milling times.

\begin{tabular}{lccllll}
\hline $\begin{array}{l}\text { Particle size (nm) } \\
\text { Milling time (h) }\end{array}$ & \multicolumn{2}{l}{ TEM results } & & \multicolumn{3}{l}{ Particle Size Analyzer results } \\
\cline { 2 - 3 } \cline { 6 - 7 } & Mean & Range & & Mean & Mode & Range \\
\hline 1 & 260 & $91-350$ & & 360 & 335 & $50-700$ \\
16 & 98 & $40-127$ & & 121 & 114 & $33-230$ \\
32 & 70 & $28-90$ & & 82 & 91 & $22-130$ \\
64 & 48 & $25-71$ & & 59 & 62 & $20-112$ \\
128 & 38 & $22-57$ & & 52 & 49 & $19-89$ \\
160 & 25 & $20-51$ & & 35 & 32 & $17-68$ \\
192 & 20 & $18-38$ & & 27 & 28 & $15-52$ \\
256 & 17 & $15-34$ & 21 & 23 & $13-32$ \\
\hline
\end{tabular}

from XRD analysis. The DTA trace corresponding to the $64 \mathrm{~h}, 128 \mathrm{~h}$, and $192 \mathrm{~h}$ milling times indicate endothermic reaction, characteristic of a glass transition followed by a sharp exothermic peak related to the crystallization process, verifying the glassy nature of amorphous phase. The intensity of the DTA crystallization peak initially increases and then reduces which this result is in good agreement with our quantitative XRD analyses.

The variations of the powder particle size at the different milling times are listed in Table 2. The results are achieved from the interpretation of TEM bright field images performed on the as-milled powders at 10 different locations and also the results obtained from the nanoparticle size analyzer. The rate of particle size reduction is initially quite rapid, but decreases with longer milling durations. Furthermore, the particle sizes distribution is reduced as they are milled for longer times. Fig. 6 displays a TEM bright field image of powders which were milled for $256 \mathrm{~h}$. The particles are semi-spherical in shape with an average size of $20 \mathrm{~nm}$ ranging from $10 \mathrm{~nm}$ to $35 \mathrm{~nm}$.

\section{Conclusions}

Calcium copper titanate powders were successfully synthesized through mechanical alloying and then their

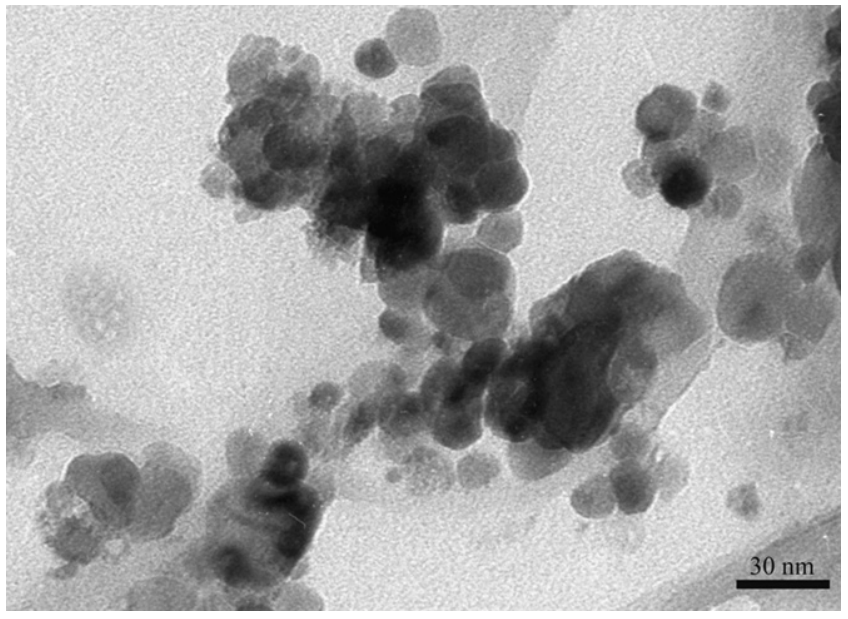

Fig. 6. TEM bright field image of the CCTO powder after $256 \mathrm{~h}$ of milling.

structure, microstructure and thermal properties were analyzed.

The following conclusions can be drawn from the work:

(1) During the milling cycle, nanocrystallization occurred rapidly and a great amount of micro-strain and lattice defects was created.

(2) In milling initiation, the initial materials were dissolved into the structure at a different rate and a significant amount of amorphous phase was formed in addition to the polymorphic transformation of anatase to sirilankite $\mathrm{TiO}_{2}$.

(3) By milling progression, the amount of amorphous phase was increased considerably and after sufficient milling time, the complete amorphization of the structure occurred.

During the heating cycle, the glass transition appeared in the powders prior to the crystallization of the amorphous phase.

(4) During the milling cycle, the nanocrystalline CCTO phase was formed by the mechano-crystallization of the amorphous phase and no evidence of its formation was detected prior to the whole amorphization of the structure.

(5) Subsequent to CCTO formation, its quantity grew considerably and the crystallite size and lattice strain were increased and reduced, respectively.

\section{References}

[1] M.A. Subramanian, D. Li, N. Duan, B.A. Resiner, A.W. Sleight, High dielectric constant in $\mathrm{ACu}_{3} \mathrm{Ti}_{4} \mathrm{O}_{12}$ and $\mathrm{ACu}_{3} \mathrm{Ti}_{3} \mathrm{FeO}_{12}$ phases, Journal of Solid State Chemistry 151 (2000) 323-325.

[2] L. Ramajo, R. Parra, J.A. Varela, M.M. Reboredo, M.A. Ramirez, M.S. Castro, Influence of vanadium on electrical and microstructural properties of $\mathrm{CaCu}_{3} \mathrm{Ti}_{4} \mathrm{O}_{12} / \mathrm{CaTiO}_{3}$, Journal of Alloys and Compounds 497 (2010) 349-353.

[3] F. Amaral, L.C. Costa, M.A. Valente, Decrease in dielectric loss of $\mathrm{CaCu}_{3} \mathrm{Ti}_{4} \mathrm{O}_{12}$ by the addition of $\mathrm{TeO}_{2}$, Journal of Non-Crystalline Solid 357 (2010) 775-781. 
[4] K.D. Mandal, R.A. Kumar, D. Kumar, O.M. Parkash, Dielectric properties of the $\mathrm{Ca}_{1-x} \mathrm{La}_{x} \mathrm{Cu}_{3} \mathrm{Ti}_{4-x} \mathrm{Co}_{x} \mathrm{O}_{12}$ system $(x=0.10,0.20$ and 0.30 ) synthesized by semi-wet route, Journal of Alloys and Compounds 478 (2009) 771-776.

[5] C.-H. Mu, P. Liu, Y. He, J.-P. Zhou, H.-W. Zhang, An effective method to decrease dielectric loss of $\mathrm{CaCu}_{3} \mathrm{Ti}_{4} \mathrm{O}_{12}$ ceramics, Journal of Alloys and Compounds 471 (2009) 137-141.

[6] S.D. Hutagalung, M.I.M. Ibrahim, Z.A. Ahmad, The role of tin oxide addition on the properties of microwave treated $\mathrm{CaCu}_{3} \mathrm{Ti}_{4} \mathrm{O}_{12}$, Materials Chemistry and Physics 112 (2008) 83-87.

[7] H. Ahmadi Ardakani, M. Alizadeh, R. Amini, M.R. Ghazanfari, Dielectric properties of $\mathrm{CaCu}_{3} \mathrm{Ti}_{4} \mathrm{O}_{12}$ ceramics improved by Chromium/ Lanthanum co-doping, Ceramics International 38 (2012) 4217-4220.

[8] Y.Q. Tan, J.L. Zhang, W.T. Hao, G. Chen, W.B. Su, C.L. Wang, Giant dielectric-permittivity property and relevant mechanism of $\mathrm{Bi}_{2 / 3} \mathrm{Cu}_{3} \mathrm{Ti}_{4} \mathrm{O}_{12}$ ceramics, Materials Chemistry and Physics 124 (2010) 1100-1104.

[9] P. Thomas, K. Dwarakanath, K.B.R. Varma, T.R.N. Kutty, Synthesis of nanoparticles of the giant dielectric material, $\mathrm{CaCu}_{3} \mathrm{Ti}_{4} \mathrm{O}_{12}$ from a precursor rout, Journal of Thermal Analysis and Calorimetry 1 (2009) 267-272.

[10] D.L. Sun, A.Y. Wu, S.T. Yin, Structure, properties, and impedance spectroscopy of $\mathrm{CaCu}_{3} \mathrm{Ti}_{4} \mathrm{O}_{12}$ ceramics prepared by sol-gel process, Journal of the American Ceramic Society 1 (2008) 169-173.

[11] F. Amaral, M. Valente, L.C. Costa, Synthesis and characterization of calcium copper titanate obtained by ethylenediaminetetraacetic acid gel combustion, Materials Chemistry and Physics 124 (2010) 580-586.

[12] A.F.L. Almeida, R.S. de Oliveira, J.C. Goes, J.M. Sasaki, A.G. Souza, J. Mendes, A.S.B. Sombra, Structural properties of $\mathrm{CaCu} 3 \mathrm{Ti}_{4} \mathrm{O}_{12}$ obtained by mechanical alloying, Materials Science and Engineering B 96 (3) (2002) 275-283.

[13] J. Xue, D. Wan, S.-E. Lee, J. Wang, Mechanochemical synthesis of lead zirconate titanate from mixed oxides, Journal of the American Ceramic Society 82 (7) (1999) 1687-1692.

[14] J. Xue, J. Wang, D. Wan, Nanosized barium titanate powder by mechanical activation, Journal of the American Ceramic Society 83 (1) (2000) 232-234.

[15] J. Wang, D. Wan, J. Xue, N.W. Beng, Synthesizing nanocrystalline $\mathrm{Pb}\left(\mathrm{Zn}_{1 / 3} \mathrm{Nb}_{2 / 3}\right) \mathrm{O}_{3}$ powders from mixed oxides, Journal of the American Ceramic Society 82 (1999) 477-479.

[16] E. Salahinejad, R. Amini, M. Marasi, T. Sritharan, M.J. Hadianfard, The effect of nitrogen on the glass-forming ability and microhardness of $\mathrm{Fe}-\mathrm{Cr}-\mathrm{Mn}-\mathrm{N}$ amorphous alloys prepared by mechanical alloying, Materials Chemistry and Physics 118 (2009) 71-75.

[17] R. Amini, E. Salahinejad, M.J. Hadianfard, M. Marasi, T. Sritharan, Characterization of $\mathrm{Fe}-\mathrm{Cr}-\mathrm{Mn}-\mathrm{N}$ amorphous powders with a wide supercooledliquid region developed by mechanical alloying, Materials Science and Engineering A 527 (2010) 1135-1142.

[18] M. Ghaffari, P.Y. Tan, M.E. Oruc, O.K. Tan, M.S. Tse, M. Shannon, Effect of ball milling on the characteristics of nano structure $\mathrm{SrFeO}_{3}$ powder for photocatalytic degradation of mMethylene blue under visible light irradiation and its reaction kinetics, Catalysis Today 161 (1) (2011) 70-77.

[19] J. Xue, J. Wang, T.M. Rao, Synthesis of $\mathrm{Pb}\left(\mathrm{Mg}_{1 / 3} \mathrm{Nb}_{2 / 3}\right) \mathrm{O}_{3}$ in excess lead oxide by mechanical activation, Journal of the American Ceramic Society 84 (2001) 660-662.

[20] B.D. Stojanovic, Mechanochemical synthesis of ceramic powders with perovskite structure, Journal of Materials ProcessingTechnology 143-144 (2003) 78-81.

[21] D. Kuscer, J. Holc, M. Kosec, Mechano-synthesis of lead-magnesiumniobate ceramics, Journal of the American Ceramic Society 89 (2006) 3081-3088.
[22] J.G. Baek, T. Isobe, M. Senna, Synthesis of pyrochlore-free $0.9 \mathrm{~Pb}\left(\mathrm{Mg}_{1 / 3} \mathrm{Nb}_{2 / 3}\right) \mathrm{O}_{3}-0.1 \mathrm{PbTiO}_{3}$ ceramics via a soft mechanochemical route, Journal of the American Ceramic Society 80 (1997) 973-981.

[23] D. Wan, J. Xue, J. Wang, Mechanochemical synthesis of $0.9\left[0.6 \mathrm{~Pb}\left(\mathrm{Zn}_{1 / 3} \mathrm{Nb}_{2 / 3}\right) \mathrm{O}_{3 z 0.4} \mathrm{~Pb}\left(\mathrm{Mg}_{1 / 3} \mathrm{Nb}_{2 / 3}\right) \mathrm{O}_{3}\right]_{0.1} \mathrm{PbTiO}_{3}$, Journal of the American Ceramic Society 83 (2000) 53-59.

[24] O. Abe, Y. Suzuki, Mechanochemically assisted preparation of $\mathrm{BaTiO}_{3}$ powder, Materials Science Forum 225 (1996) 563-568.

[25] S.K. Manik, S.K. Pradhan, Microstructure characterization of ballmill-prepared nanocrystalline $\mathrm{CaCu}_{3} \mathrm{Ti}_{4} \mathrm{O}_{12}$ by Rietveld method, Physica E 33 (2006) 160-168.

[26] R.S. Winburn, D.G. Grier, G.J. Mccarthy, Rietveld quantitative X-Ray diffraction of NIST fly ash standard reference materials, Powder Diffraction 15 (2000) 163-172.

[27] A.G. De La Torre, S. Bruque, M.A.G. Aranda, Rietveld quantitative amorphous content analysis, Journal of Applied Crystallography 34 (2001) 196-202.

[28] S. Kemethmuller, A. Roosen, F. Goetz-Neunhoeffer, Quantitative analysis of crystalline and amorphous phases in glass-ceramic composites like LTCC by the Rietveld method, Journal of the American Ceramic Society 89 (2006) 2632-2637.

[29] M.L. Gualtieri, M. Prudenziati, A.F. Gualtieri, Quantitative determination of the amorphous phase in plasma sprayed alumina coatings using the Rietveld method, Surface and Coatings Technology 201 (2006) 2984-2989.

[30] P.S. Whitfield, L.D. Mitchell, Quantitative Rietveld analysis of the amorphous content in cements and clinkers, Journal of Materials Science 38 (2003) 4415-4421.

[31] L. Lutterotti, P. Scardi, P. Maistrelli, LS1-A computer program for simultaneous refinement of material structure and microstructure, Journal of Applied Crystallography 25 (1992) 459-462.

[32] H. Dutta, Y.-C. Lee, S.K. Pradhan, Microstructure characterization and polymorphic transformation kinetic study of ball-milled nanocrystalline $\mathrm{a}-\mathrm{TiO}_{2}-20 \mathrm{~mol} \% \mathrm{~m}-\mathrm{ZrO}_{2}$ mixture by X-ray diffraction and electron microscopy, Physica E 36 (2007) 17-27.

[33] P. Bose, S.K. Pradhan, S. Sen, Rietveld analysis of polymorphic transformations of ball milled anatase $\mathrm{TiO}_{2}$, Materials Chemistry and Physics 80 (2003) 73-81.

[34] R.A. Young, D.B. Wiles, Profile shape functions in Rietveld refinements, Journal of Applied Crystallography 15 (1982) 430-438.

[35] R. Amini, M.J. Hadianfard, E. Salahinejad, M. Marasi, T. Sritharan, Microstructural phase evaluation of high-nitrogen $\mathrm{Fe}-\mathrm{Cr}-\mathrm{Mn}$ alloy powders synthesized by the mechanical alloying process, Journal of Materials Science 44 (2009) 136-148.

[36] R. Ren, Z. Yang, L.L. Shaw, Polymorphic transformation and powder characteristics of $\mathrm{TiO}_{2}$ during high energy milling, Journal of Materials Science 35 (2000) 6015-6026.

[37] S. Begin-Colin, T. Girot, G. Le Caer, A. Mocellin, Kinetics and mechanisms of phase transformations induced by ball-milling in Anatase $\mathrm{TiO}_{2}$, Journal of Solid State Chemistry 149 (2000) 41-48.

[38] S.M. Klein, J.H. Choi, D.J. Pine, F.F. Lange, Synthesis of rutile Titania powders: agglomeration, dissolution, and reprecipitation phenomena, Journal of Materials Research 18 (6) (2003) 1457-1464.

[39] J. Eckert, L. Schultz, K. Urban, Progress of quasicrystal formation during mechanical alloying in $\mathrm{Al}-\mathrm{Cu}-\mathrm{Mn}$ and the influence of the milling intensity, Zeitschrift fur Metallkunde 81 (1990) 862-868.

[40] D. Kuscer, E.T. Sturm, J. Kovac, M. Kosec, Characterization of the amorphous phase and the nanosized crystallites in high-energy-milled lead-magnesium-niobate powder, Journal of the American Ceramic Society 92 (6) (2009) 1224-1229. 